\title{
Evaluating Creative Mobile Applications Development Using Emotional Design
}

\author{
Nixon Muganda Ochara \\ University of Pretoria \\ School of Information Technology \\ Department of Informatics \\ +27(12) 4203373 \\ nixon.ochara@up.ac.za
}

\author{
Carina De Villiers \\ University of Pretoria \\ School of Information Technology \\ Department of Informatics \\ +27(12) 4203798 \\ carina.devilliers@up.ac.za
}

\author{
Jaco Pretorius \\ University of Pretoria \\ School of Information Technology \\ Department of Informatics \\ $+27(12) 4203798$ \\ Jaco.Pretorius@up.ac.za
}

\author{
Hossana Twinomurinzi \\ University of South Africa \\ School of Computing \\ College of Science, Engineering and \\ Technology \\ +27(11) 6709361 \\ twinoh@unisa.ac.za
}

\begin{abstract}
In this research paper, we adopt an integrative view of user involvement in software development; where, a user's psychological state, at various phases of development, is linked to the contribution of user involvement in the success of software development. We explore the link between creativity and emotional design in order to evolve a conceptual framework for studying creativity in the fast growing area of mobile applications (apps) development. Action research, which is regarded as participatory, emancipatory and contextual, was adopted in this study. The study used a case study design and a survey of 1,502 students registered for a first year course in Management Information Systems at a large urban University in South Africa. Results from this study found that for app development to be more creative and innovative, emotional design should be part of the broader process of improving requirements engineering in Information Systems Development (ISD). We also found that in situations where emotional feedback is genuine, requirements engineering problems related to the "misinformation effect" common in ISD can be minimized. The third claim we affirm stronger is how users in ISD play a closer role as co-developers of mobile apps in order to realize true creativity and innovativeness. This study further demonstrated how subjective feelings in ISD can be evaluated using visual artifacts such as the Emocard.
\end{abstract}

\section{Categories and Subject Descriptors}

D.2.1 Requirements/Specifications: Elicitation methods (e.g., rapid prototyping, interviews, JAD; Languages; Methodologies (e.g., object-oriented, structured); Tools

\section{General Terms}

Information Systems Development

\section{Keywords}

Creativity, Software Development, Emotional Design, Mobile Applications Development; Creative Design

\section{INTRODUCTION}

A critical raison d'être for the success of software development projects is premised on user involvement. However, over the years, the contribution and role of user involvement continue to be contested (Henfridsson \& Lindgren, 2010). Conceptually, classic user involvement is viewed as a subjective psychological state reflecting the importance and personal relevance of a system to a user (Hartwick \& Barki, 1994). A much more contemporary view is; where contact with users at various phases of the systems development process is reified (Henfridsson \& Lindgren, 2010). The research reported in this paper adopts a much more integrative view; where, a user's psychological state, at various phases of development, is linked to the contribution of user involvement in the success of software development.

The hybrid view resonates with the philosophical perspective in software development movements such as agile development and extreme programming (XP) that there is increasing humanity and effectiveness in software development (Beck \& Andres, 2004; Gruner, 2011). The concept of humanity of software systems is intricately interwoven with the psychological state of recipients (individuals, organizations) of software solutions. We see creativity as a critical component of humanity in software development, and Pyshkin (2014) recognizes it as a product of art and human creativity. O'Bower (1997) also elevates the notion of creativity as the only crucial ability required in programming; while Sergei Arkhipenkov states that "software development is a kind of human activity which is mistakenly attributed to engineering" (Arkhipenkov, 2012).

Creativity in software development is justified on the basis that users seek value from solutions that are presented to them. Value propositions in software development are not limited to basic software features alone; but should also consider propositions related to performance and excitement (for distinctions, see Terninko1, 1995). The basic and performance features are

\footnotetext{
${ }^{1}$ Basic features are those that the product type is expected to deliver. A basic feature of a mobile phone, for example, is a database function to store telephone numbers. Performance features are those that
} 
typically captured through structured and formalized requirements elicitation approaches and designed into the system. However, the third aspect, that is, building excitement features in software development products is much more elusive and is linked to creativity in the development process. We see creativity as instrumental in designing software solutions that surprises users due to one or more 'excitement features' (Mann, 2002; Desmet, Porcelijn, \& Van Dijk, 2007). However, capturing and evaluating user's excitement about a sofware concept or feature still remains problematic and research in this area is nascent.

\subsection{Research objective}

This study, in line with Desmet, Porcelijn, \& Van Dijk (2007) research, seeks to investigate how creativity in app development can enhance the evaluation of user excitement.

The key research question is: How can creativity in design enhance user involvement?

We consider creativity to be the "generation of a product that is judged to be novel and also to be appropriate, useful, or valuable by a suitably knowledgeable social group" (Sawyer, 2012, p. 8). This is a sociocultural conceptualization of creativity that takes into account that software development efforts in organizational setups are typically group innovations involving structures and processes of organizational systems. The purpose of the study is addressed by, first, enumerating on the theoretical link between creativity and emotional design as the basis of enabling 'exciting' software solutions. A research model is then proposed that captures these linkages. The paper then describes the research context, methodology, results and then discusses the implications and future research directions.

A key assumption that is made in studying processes of creativity is that a creative 'event' actually occurs. This is not always the case, not only because there is no guarantee that the event occurs, but also the difficulty of identifying a solution as creative (Dorst \& Cross, 2001). However, part of the study undertaken here is premised on the second assumption and the solution envisaged in this paper should partially addressed this concern.

\section{CREATIVITY IN EMOTIONAL DESIGN}

In this section, the link between creativity and emotional design will be established in order to evolve a conceptual framework for studying creativity in app development. The starting point is to anchor the conception of creativity on an action theory person, in which Sawyer (2012, p.88) makes the point that: "Creativity takes place over time, and most of the creativity occurs while doing the work. The medium is an essential part of the creative process, and creators often get ideas while working with the materials". Two key highlights of this sociocultural conceptualization of creativity from an action theory perspective are that in creativity: the product or process must be novel, and it must be appropriate to some domain of activity. The notion of novelty must be adjudged by experts as appropriate in a particular domain.

differentiate between competing products. Mobile phones have performance features such as weight, screen size, and stand-by time. The third type of features, excitement features, are those that the consumer did not expect to see in the product and is excited to learn are there.
Csikszentmihalyi (1999) has aptly crystallized ideas of the soiocultural conception of creativity in his General Systems Model of Creativity (Fifure 1). He recognizes that in any creative process, a person begins the creative process by developing a created product or solution. The individual in the creative process relies on a repertor of personality and cognition that define their background. However, the individual's effort is not adequate in adjudging creativity as either appropriate or novel. This is because the individual operates within a social system, and however inspired or creatively-trained the individual, the adjudgement of appropriateness and novelty of creativity is left to the "experts" within a particular domain in the social system. The field is created by a group of experts or the people who are evaluating the creative product. For instance during the process of developing an information systems innovation, users are engaged in various ways to help in shaping the innovation to be acceptable for organizational use. Therefore creativity is argued to be a product of the dynamic interaction among three dimensions: the individual, the domain, and the field (Csikszentmihalyi, 1999).

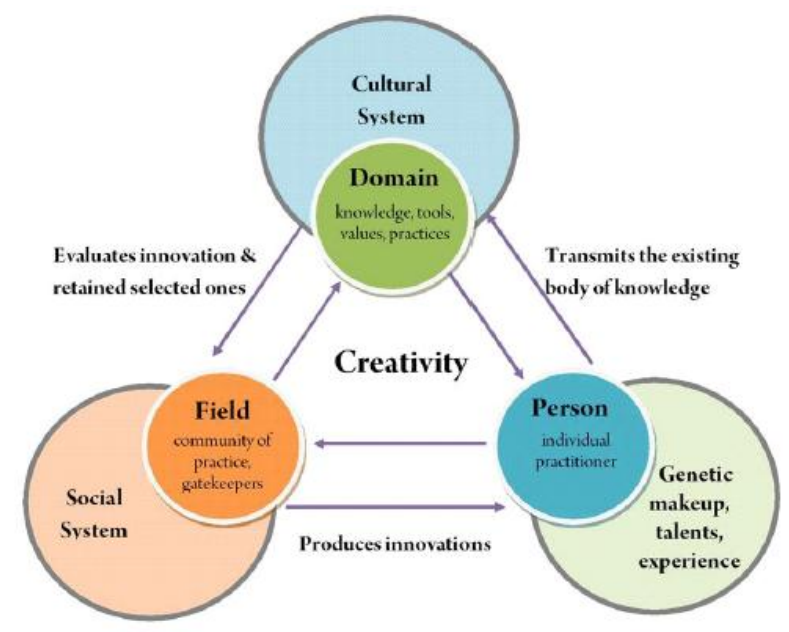

Figure 1. General Systems Model of Creativity (Source: Csikszentmihalyi, 1999)

However, the process of adjudging an innovation as novel is not as clear-cut as envisaged in the creativity process. For instance, how do the users determine that a particular concept, idea, innovation or feature of an innovation is "novel"? Novelty has to do with "newness" and must evoke surprise from the experts. We argue that in the process of assessing "newness" or novelty, the "materials" used in the process of evaluation plays a critical role in capturing 'moments of insight' during the process of software applications development. Thus in an attempt to link 'novelty' as an outcome of the creative process, we recourse to research that have established that usability is correlated to aesthetics (see Tractinsky, Katz, \& Ikar, 2000; Tractinsky, 1997; (Hassenzah \& Tractinsky, 2006; Tractinsky, 2004).

Aesthetics and its evaluation largely through emotions are interwoven, yet research confirms that emotions play a critical role in people's daily lives. For instance, emotions play a role in assessing whether situations are good or bad, safe or dangerous and they also aid in decision making (Norman, 2007). If emotions play a role in decision making, the implication is that they influence product or software designs. Norman (2007) and 
Tractinsky (2004) have found a direct correlation between the attractiveness (aesthetic appeal) of things to not only increased usability but also to creativity. Thus more attractive design inspires more creativity in not only designers but users of the product and this is likely to have a profound effect especially in situations where designers seek feedback from users.

In assessing or evaluating situtions, the human brain operates at three levels: the visceral, behavioral and reflective levels (Norman, 2007). The visceral level is considered to be the prethought, preconsicious level, where appearance and first impressions are formed. Thus, in terms of design consideration, focus is on the initial impact of a produc or solution by assessing the appearance, touch and feel. The second level, behavioral level is about product function, performance and usability. The third reflective level of consciousness is where feeling, emotions, and cognition reside. That at this level, the full impact of both thought and emotions is experienced. Norman ( 2007) further contends that at the lower visceral and behavioral levels, there is only affect, but without interpretation or consciousness, yet interpretation, understanding, and reasoning come from the reflective level which is much more vulnerable to variability through culture, experience, education, and individual differences.

But what do all these mean for this study? Recent research in $\mathrm{HCI}$ appears to be advocating for designs that seek a fit between technology and human values in which emotional considerations are key (Kamil \& Abidin, 2013); emotional elements in design aid in initiating behavior and motivate decisions (Olsson \& Salo, 2012); designing for the pleasurable life and the good life (Desmet \& Hassenzahl, 2012); and focus on excitement as a basis of designing products which evoke a 'wow' emotional response from customers (Desmet \& Pohlmeyer, 2013). In addition, the emphasis emanating from such studies appear to be much more user-oriented and holistic, and takes into the account the 'wow' impact of a product, not only at the conceptual level but also at the feature level. The result is a user engagement process that elicits a unified product concept in which visual appearance, interaction and features are aligned to elicit a coherent experience (Desmet, Porcelijn, \& Van Dijk, 2007).

Thus, we consider emotional design to refer to approaches in applications development that take into account human values, emotional elements and excitement as foundational elements for creating novel products. Thus the design considers three levels at which the human brain functions: viscral, behavioral and reflective levels; which consequetively map product characteristics of appearance, pleasure and effectiveness of use and aspects related to self-image, personal satisfaction and memories. That the key to determining whether or not such characteristics exist in design (software or physical products) are related to positive or negative emotions that customers experienve as they interact with the product. The sociocultural notion of creativity and emotional design from psychology has given traction to our focus on how 'wow' experiences can be useful in

Permission to make digital or hard copies of all or part of this work for personal or classroom use is granted without fee provided that copies are not made or distributed for profit or commercial advantage and that copies bear this notice and the full citation on the first page. To copy otherwise, or republish, to post on servers or to redistribute to lists, requires prior specific permission and/or a fee.

Conference'10, Month 1-2, 2010, City, State, Country.

Copyright 2010 ACM 1-58113-000-0/00/0010 ...\$15.00. evaluating the novelty of design during applications development.

Desmet, Porcelijn, \& Van Dijk (2007) define 'wow' as an affective, emotional experience or a valenced experience that includes an unpleasant or a pleasant feeling. Emotions that may constitute a wow experience can be linked to: a subjective feeling, a facial and bodily expression, a change in arousal, and a motivational tendency (see Lazarus, 1991). Desmet, Porcelijn, \& Van Dijk (2007) on the other hand consider that for 'wow' to be subjected to analytical focus, it needs to be considered as a composite of several emotions related to: pleasant surprise, desire, and fascination. Though there are a number of 'wow' models in the literature, we adopted the typology of emotions types by Desmet that are typically used to assess customer experience in response to consumer products. The descriptions of the themes of the typology of 'wow' is provided by Desmet, Porcelijn, \& Van Dijk (2007) below:

On the basis of reported appraisal themes, Desmet (2003a) developed a typology of emotion types that we generally experience in response to consumer products. Five of these types represent pleasant emotions, and threeof these five are considered to combine to a wowexperience: pleasant surprise, fascination, and desire.

- Pleasant surprise: We experience surprise in response to products that we appraise as novel, both in terms of suddenness and unexpectedness. To experience pleasant surprise, the product must be appraised as unexpected and as suddenly matching a concern.

- Fascination: We experience fascination in response to products that we appraise as unfamiliar. If the product touches on our need of curiosity, we will experience the pleasant sense of unfamiliarity that we call fascination.

- Desire: We desire for products that we appraise as fit objects that call for possession. The product is appraised as a fit object because using or owning it will fulfill a goal, its design is delightful or it expresses some desirable quality.

In summing our conceptual argument, we therefore evolve the following research questions as guide to this study:

- $\quad$ To what extent does the emotion of pleasant surprise (or the negative emotion associated with it) eorrelate to novelty in creative design in applications development?

- To what extent does the emotion of fascination (or the negative emotion associated with it) eorrelate to novelty in creative design in applications development?

- To what extent does the emotion of desire (or the negative emotion associated with it) eorrelate to novelty in creative design in applications development?

We explore these questions by undertaking a case study in which groups of students were tasked with conceptualizing and designing apps using the design thinking approach. Design thinking is an approach to problem solving that integrates empathy and creativity to solving existing problems within their context (Rowe, 1991).

\section{METHODOLOGY 3.1 Research Design}


Action research, which is regarded as participatory, emancipatory and contextual, was adopted in this study. Action Research is research in which the "researcher generates new knowledge about a social system, while at the same time attempting to change it in a quasi-experimental fashion... with the goal of improving the social system". (Lewin, 1946). The research was participatory, since the researchers in the study were the educators involved in teaching the creative app development to the business students at a large urban South African university based in the administrative capital, Pretoria. The study is emancipatory, since the educators involved sought to make the course, with over 1,502 students much more engaging. Therefore at the beginning of 2013, the educators involved in the teaching of the course resolved to address the problem of lack of effective engagement in large classes by introducing app development from a creative design perspective. The issue of context can be argued from the focus of the study, i.e. students majoring in Informatics as a Business Degree at the case study university. The study used a case study design and a survey among 1800 students registered for a first year course in Fundamentals of Information Systems at a large urban University in South Africa.

\subsection{Research Participants}

The total population for the case study and survey component comprised of 1,502 business students. The course has a coordinator, three theory educators, and two practical tutors. Typically, a theory lecture would be delivered by an instructor after which the students would work at their own time and do presentations to other groups of student users during creative practical assignment to be completed in the computer labs. During these interactive sessions, the practical educators and tutors would be present to facilitate the process. The course runs from February to June and is offered to students taking Information Systems. The students peer-reviewed their own work and served as evaluators. The participants that were targeted for the survey were Informatics students, who have a business orientation to computing and who take up professional appointments as business/systems analysts on completion of their studies. The survey data was collected during the first half of 2013 (February to June). Out of a class population of 1,502 students, usable responses were obtained from 1,100 students, giving a response rate of $87 \%$. However, given the interpretive nature adopted in this study, a simple random sample of 218 responses were analysed to present the results reported here.

\subsection{Research Materials}

Data from surveys and interviews formed the primary source of information for this study. Data was gathered using an Emocard tool (Figure 2.) The interview transcripts were coded by the two practical tutors who were involved in administering the survey instruments. A comparison of the transcripts and how they mapped to the themes was done to ensure reliability in the coding process. In addition, survey data was used to capture descriptive aspects of the study such as visual feedback obtained from the

Permission to make digital or hard copies of all or part of this work for personal or classroom use is granted without fee provided that copies are not made or distributed for profit or commercial advantage and that copies bear this notice and the full citation on the first page. To copy otherwise, or republish, to post on servers or to redistribute to lists, requires prior specific permission and/or a fee.

Conference'10, Month 1-2, 2010, City, State, Country.

Copyright 2010 ACM 1-58113-000-0/00/0010 ...\$15.00. apps that were being developed by the students divided into groups of five each.

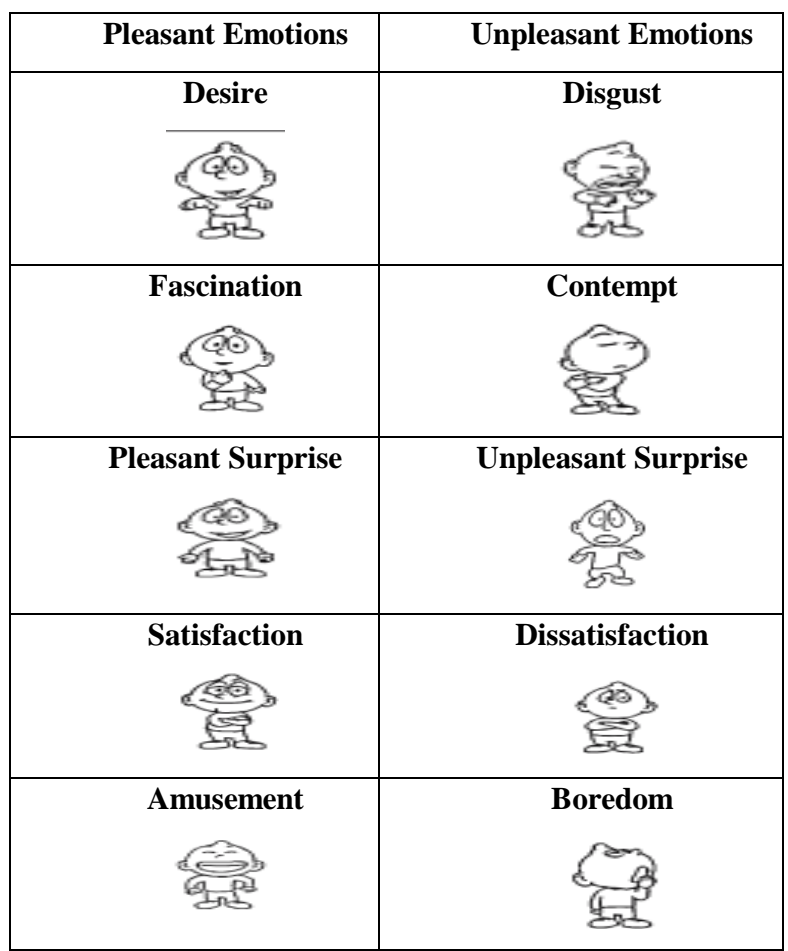

Figure 2: Emocard (Source: Desmet, Porcelijn \& van Dijk, 2007)

\subsection{Action (Design) Research Procedure}

Design research inherits its principles from action research with its main uniqueness being that design research requires the creation of an artefact unlike in action research whose emphasis is on a change (Romme, 2004). Since the study involved the creation of an app, design thinking was more appropriate as the action research method.

The design research process involved a number of phases: planning, action and reflection. In the Planning (Focus on Learner and Strategies) phase of the action research process (after (Boud \& Walker, 1990), the staff members of the department of Information Systems held a planning session in October 2012, during which the problem was diagnosed as lack of engagement in large classes. The strategy of coming up with practical creative design workshops for developing was mooted and implemented in the semester that started in February 2013.

There were a series of eight workshops (though the activities in each were iterative) comprising of the following phases:

- $\quad$ Phase I: Introductory workshop on Design Thinking

- Phase II: Define: Identify and define the challenge

- Phase III: Research: Reframe challenges to opportunities; full spectrum data gathering.

- Phase IV: Ideation: Using radical techniques for brainstorming ideas with end users

- Phase V: Prototype: Form creative partnerships; prototype. 
- $\quad$ Phase VI: Choose: Review objectives; select powerful ideas

- Phase VII: Implement: Select and assign tasks, determine resources, execute and deliver to client.

- Phase IIX: Learn: Gather feedback; determine if solution met goals; discuss improvements; measure success; document.

\subsection{Data Analysis}

The primary mode of analysis was thematic analysis. There are two versions of thematic analysis: inductive and theoretical thematic analysis (Braun \& Clarke, 2006). In an inductive approach, the themes identified are strongly linked to the data themselves, which in the end may bear little relationship to the specific questions that were asked of the participants (Braun \& Clarke, 2006). The themes identified in the inductive approach would not be driven by the researcher's theoretical interest in the area or topic. Theoretical thematic analysis on the other hand is driven by the researcher's theoretical or analytic interest in the area and is thus more explicitly analyst-driven (Braun \& Clarke, 2006). The theoretical themes used in the analysis relate to the categorization of feedback based on four themes:

- Notable Innovations - Relate to positive feeling about the mobile applications and is identified in terms of the good things about the innovation.

- Actionable Criticism - Relate to positive criticism, in which respondents spell out what needs to be done to improve the mobile application

- Negative Criticism - Relate to unanswered questions about the innovation that leaves the respondent baffled and unable to comprehend a number of things about the innovation.

- New Possibilities - These relate to new ideas that the respondents bring out that were not considered before in the applications development.

\section{ANALYSIS OF RESULTS}

The feedback from Emocard template that was used to capture the experience regarding the mobile application development process was obtained from 218 respondents. The part of the Emocard showing the emoticons was analyzed statistically in order to explain the significance of the statistics to the overall objective of the study: to assess the effectiveness of emotional design and its relevance to the development of creative mobile applications. In the first part of the Emocard instrument (based on Figure 2), respondents selected the appropriate feeling after hearing the "story" regarding the application and seeing a presentation and a demonstration of the application from the designers of the

Permission to make digital or hard copies of all or part of this work for personal or classroom use is granted without fee provided that copies are not made or distributed for profit or commercial advantage and that copies bear this notice and the full citation on the first page. To copy otherwise, or republish, to post on servers or to redistribute to lists, requires prior specific permission and/or a fee.

Conference'10, Month 1-2, 2010, City, State, Country.

Copyright 2010 ACM 1-58113-000-0/00/0010 ...\$15.00. application. The Emocard section with the emoticons was structured as a Likert - type scale, with a choice of 1 - indicating that the respondent had a positive feeling, supportive of the application; a 2- indicative of a neutral feeling; while a 3 indicated a negative feeling, not supportive of the "story", presentation and demonstration of the mobile application being presented by the designers.

The second part of the Emocard instrument captured written feedback from the respondents about their feelings about the mobile application. The written feedback was theoretically analyzed by categorizing under the main themes of "notable innovations", "actionable criticism", "negative criticism" and "new possibilities". The analysis that follows seeks to demonstrate the effectiveness of using emotional design, based on the Emocard, in mobile applications development.

\subsection{Descriptive Analysis}

Figure 3 shows the distribution of the emotions based on the selections made by the 218 respondents of the study. Satisfaction (S), Pleasant Surprise (P) and Amusement (A) were each represented at 25 percent; while Desire (D) was at percent and Fascination $(F)$ at 13 percent. Figure 4 captures a how the responses clustered around the theoretical themes. Selected emotions which were closer to 1 were indicative of "Notable Innovations"; while those that were closer to 3 were indicative of "New Possibilities". Responses that pointed to "Actionable Criticism" were typically clustered around 1.5; while those considered as "Negative Criticism" were closer to 2.

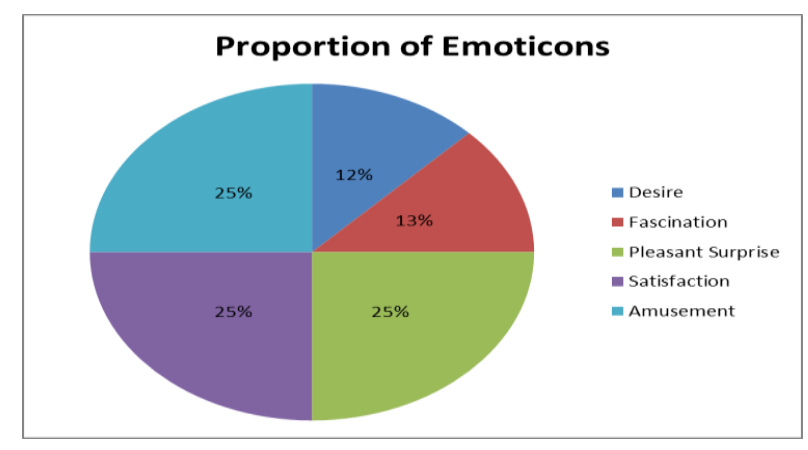

Figure 3. Distribution of Emotions

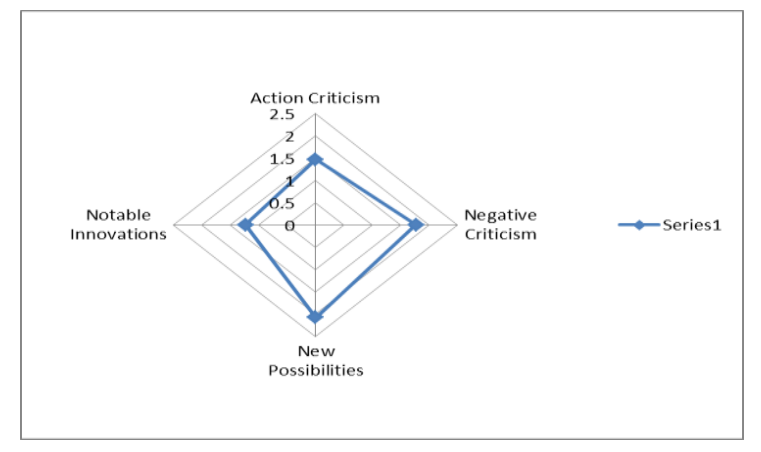

Figure 4. Kiviat Diagram of Assessment Levels

Table 1 captured summary statistics of the themes relative to the selected emotions. Bases on the feedback provided by the respondents using theoretical thematic analysis, out of 218 respondents, the feedback from 93 respondents pointed to mobile applications, which were considered to be under the theme of 
"Actionable Criticism". Key emotions critical in identifying such applications, based on frequency are Desire (1.25), Fascination (1.40), \& Satisfaction (1.33). However, there were also mild feelings of Pleasant Surprise (1.69) and mild Amusement (1.69). Thus critical feelings that can be associated with "Actionable Criticism" are D, F, and S.

Table 1. Descriptive Statistics

\begin{tabular}{|l|r|r|r|r|r|l|l|}
\hline Theme & D & F & P & S & A & Cnt & Av. \\
\hline Actionable & $\mathbf{1 . 2 5}$ & $\mathbf{1 . 4 0}$ & 1.69 & $\mathbf{1 . 3 3}$ & 1.69 & 93 & 1.47 \\
Criticism & $(\mathbf{1})$ & $(\mathbf{3})$ & $\mathbf{( 4 )}$ & $(\mathbf{2})$ & $\mathbf{( 4 )}$ & & \\
\hline Negative & 1.49 & 1.74 & 1.82 & 1.75 & 2.04 & 57 & 1.77 \\
Criticism & $(\mathbf{1})$ & $\mathbf{( 2 )}$ & $\mathbf{( 4 )}$ & $\mathbf{( 3 )}$ & $\mathbf{( 5 )}$ & & \\
\hline New & 2.00 & 1.90 & 2.35 & 2.00 & 2.10 & 18 & 2.07 \\
Possibilities & $\mathbf{( 2 )}$ & $\mathbf{( 1 )}$ & $\mathbf{( 3 )}$ & $\mathbf{( 2 )}$ & $\mathbf{( 4 )}$ & & \\
\hline Notable & $\mathbf{1 . 0 4}$ & $\mathbf{1 . 1 6}$ & $\mathbf{1 . 3 2}$ & $\mathbf{1 . 1 6}$ & $\begin{array}{c}1.46 \\
\mathbf{( 4 )}\end{array}$ & 50 & 1.23 \\
Innovation & $\mathbf{( 1 )}$ & $\mathbf{( 2 )}$ & $\mathbf{( 3 )}$ & $\mathbf{( 2 )}$ & $\mathbf{( 4 )}$ & \\
\hline
\end{tabular}

50 respondents feedback pointed to applications that fall under the category of "Notable Innovations". Critical emotions linked to notable innovations based on the feedback from respondents are Desire (1.04), Fascination (1.16), Satisfaction (1.16) and Pleasant Surprise (1.32); with mild feelings of Amusement (1.46). Therefore in assessing using feedback regarding "Notable Innovations", the four critical emotions are D, F, P, S. 57 respondents indicated gave feedback that some of the applications are under the category of "Negative Criticism" - i.e. applications that are highly criticized, but could still be redesigned to be acceptable. Of note in the feedback regarding "Negative Criticism" applications were that all the feelings were mild, but with three orienting towards positive emotions, i.e. mild feelings of Desire (1.49), Fascination (1.74), Pleasant Surprise (1.82) and Satisfaction (1.75). However, the fourth feeling gravitated towards Boredom (2.04). Thus, designers need to be aware of user feedback that borders on the borderline either on the positive or the negative aspects of the emotions.

The fourth category of feedback was provided for 18 applications and placed under the category of "New Possibilities". All the associated feelings were oriented towards unpleasant emotions. Their weightings were as follows Disgust (2.00), Content (1.90), Unpleasant Surprise (2.35), Dissatisfaction (2.00) and Boredom (2.10). Applications, which were placed under "New Possibilities", are those that are not meeting current needs, thus designers need to consider new designs which maybe unrelated to the current design. Typical feedback associated with such designers point out several unanswered questions by users as they seek to understand the rationale of the current application. This may call for a rethink of the current design and consider other alternatives which had not been considered before.

\subsection{Evaluating Qualitative Feedback}

In this section, the categorization under the four themes (Notable

Permission to make digital or hard copies of all or part of this work for personal or classroom use is granted without fee provided that copies are not made or distributed for profit or commercial advantage and that copies bear this notice and the full citation on the first page. To copy otherwise, or republish, to post on servers or to redistribute to lists, requires prior specific permission and/or a fee.

Conference'10, Month 1-2, 2010, City, State, Country.

Copyright 2010 ACM 1-58113-000-0/00/0010 _..\$15.00.
Innovations, Actionable Criticism, Negative Criticism and New Possibilities) is further explored using a qualitative data analysis process. A theoretical thematic analysis is undertaken in which raw feedback is linked to the various themes and emotional feedback in order to understand how to use both the visual feedback with the oral/written feedback by users involved in the requirements engineering process.

\subsubsection{Realizing "Notable Innovations"}

Notable innovations are realized when the respondents experience a pleasant feeling about the application being developed. After going through a process of user involvement throughout the development process, the user(s) are engaged in a process of "story telling" about the presentation; features of the presentation are also demonstrated and a presentation on the application is also conducted. The feedback should not only comprise pleasant feelings (notably D, F, P, S) as discovered in the priori analysis; but there should also be "good things" said about the application, not only related to the features but also the application as a whole. Table 2 captures sample feedback that was construed to point to some notable innovations that were displayed by various groups.

Table 2 Realizing "Notable Innovations"

\begin{tabular}{|c|c|c|}
\hline Ref & Text: Excerpts & Discursive Analysis \\
\hline R1 & $\begin{array}{l}\text { [...]App will help people } \\
\text { to learn how to draw; the } \\
\text { title draws in a person's } \\
\text { attention; user friendly; the } \\
\text { ideas show in the app } \\
\text { "spark"; want is satisfied. }\end{array}$ & $\begin{array}{l}\text { Where all the selection } \\
\text { was pleasant emotions, the } \\
\text { respondents highlighted } \\
\text { things that were notable } \\
\text { about the innovation, } \\
\text { reinforcing the strong } \\
\text { points of the applications } \\
\text { development process. }\end{array}$ \\
\hline $\mathrm{R} 2$ & $\begin{array}{l}\text { I am very impressed } \\
\text { especially as an accounting } \\
\text { student. It will also help } \\
\text { ordinary people be able to } \\
\text { budget better as credit } \\
\text { issues are escalating in } \\
\text { RSA. }\end{array}$ & $\begin{array}{l}\text { Again, where all the } \\
\text { pleasant feelings were } \\
\text { selected, the feedback } \\
\text { typically pointed out all } \\
\text { the notable things about } \\
\text { the innovation }\end{array}$ \\
\hline R3 & $\begin{array}{l}\text { [...] Very impressed with } \\
\text { the overall idea of the app. } \\
\text { I would like to use this app } \\
\text { in my everyday life. I } \\
\text { found it very innovative } \\
\text { and useful. It could change } \\
\text { /help my daily life in a } \\
\text { small way. }\end{array}$ & $\begin{array}{l}\text { Impressive comments } \\
\text { about the innovation also } \\
\text { linked to desire, } \\
\text { fascination } \\
\text { satisfaction, with mild } \\
\text { feelings of pleasant } \\
\text { surprise and amusement. }\end{array}$ \\
\hline $\mathrm{R} 4$ & $\begin{array}{l}\text { The application was very } \\
\text { creative. I was very } \\
\text { impressed with the } \\
\text { innovative ideas. I would } \\
\text { use the app. The } \\
\text { terminology used is at a } \\
\text { high level. They have a } \\
\text { wide knowledge of } \\
\text { informatics use in our daily } \\
\text { lives. }\end{array}$ & $\begin{array}{l}\text { Where all the selection } \\
\text { was positive emotions, the } \\
\text { respondents highlighted } \\
\text { things that were notable } \\
\text { about the innovation, } \\
\text { reinforcing the strong } \\
\text { points of the applications } \\
\text { development process. }\end{array}$ \\
\hline
\end{tabular}

The response in R1 does not only mention specific functionalities and features that are visible in the application; but the respondent 
goes on to comingle the feedback with their selection of pleasant feelings (all were positive) with words that communicate feelings such as "spark" and satisfaction. R2, R3 and R4 also reinforce the notion that where only pleasant emotions were selected (except in R3 where there was a selection of mild feelings of pleasant surprise) the feedback captured notable things about the application which were emphasized with words that reinforced that these were notable innovations. For instance, R2, not only recognized that the innovation would make 'budgeting' better, but was also 'impressed' in her assessment of the application. R3 even used the words 'very impressed' and as well, recognized that the application was 'very innovative'; feedback, which to a developed would sound very supportive of the effort. R4 actually recognized that the application was not only creative but also very creative as well.

The emotions and feedback expressed by R1, R2, R3, and R4 may be subjective, but research has discovered that the process of emotion is universal and that people that share concerns and ideas in an appraisal process may experience similar emotions to a given issue (Desmet \& Hassenzahl, 2012). In the cases above, the similar use of words to express emotions after selecting similar emoticons in the Emocard provides clarity to this process, especially due to the fact that the respondents were reacting to different applications being made by different groups.

\subsubsection{Recognizing "Actionable Criticisms"}

In responses that were related to "Actionable Criticisms (Table 3), the pleasant feelings that were expressed predominantly related to $\mathrm{D}, \mathrm{F} \& \mathrm{~S}$ (Table 1); while the written and oral feedback was focused on what the application developers ought to do to improve the mobile application.

Table 3 Recognizing "Actionable Criticisms"

\begin{tabular}{|c|c|c|}
\hline Ref & Text: Excerpts & Discursive Analysis \\
\hline R5 & $\begin{array}{l}{[. .] \text { If executed properly, }} \\
\text { the application could be } \\
\text { very efficient, successful } \\
\text { and helpful to the economy } \\
\text {-We need to make the app } \\
\text { accessible to poor people } \\
\text { as well } \\
\text {-How do we plan to } \\
\text { generate revenue from the } \\
\text { application? }\end{array}$ & $\begin{array}{l}\text { Where there were } \\
\text { actionable comments, } \\
\text { there were feelings of } \\
\text { desire, fascination, } \\
\text { satisfaction, mild feelings } \\
\text { (pleasant surprise, } \\
\text { amusement) }\end{array}$ \\
\hline R6 & $\begin{array}{l}{[\ldots] \text { Make sure the idea is }} \\
\text { made appealing to all } \\
\text { students. Provide extra } \\
\text { lines on the app that will } \\
\text { enable students to } \\
\text { recommend new meals to } \\
\text { be added on the menu. }\end{array}$ & $\begin{array}{l}\text { Positive, "actionable" } \\
\text { criticism is linked to } \\
\text { feelings of desire; pleasant } \\
\text { surprise and satisfaction, } \\
\text { even though there may be } \\
\text { slight feelings of } \\
\text { fascination } \\
\text { amusement. }\end{array}$ \\
\hline $\mathrm{R} 7$ & $\begin{array}{l}\text { Should change } \\
\text { downloading for free to } \\
\text { avoid piracy. Avoid too } \\
\text { many things in the app } \\
\text { since it could 'blue' target } \\
\text { market and hike cost. }\end{array}$ & $\begin{array}{l}\text { Emotions of desire, } \\
\text { fascination, satisfaction } \\
\text { and slight feelings of } \\
\text { pleasant surprise and } \\
\text { amusement elicited } \\
\text { feedback that could be } \\
\text { construed to be positive or } \\
\text { actionable. }\end{array}$ \\
\hline R8 & The app is clever, helpful, & Clear positive comments \\
\hline
\end{tabular}

\begin{tabular}{|l|l|l|}
\hline $\begin{array}{l}\text { informative, accessible but } \\
\text { not foolproof. Need to } \\
\text { solve the problem. }\end{array}$ & $\begin{array}{l}\text { linked to emotions of } \\
\text { fascination and } \\
\text { satisfaction, with mild } \\
\text { emotions of desire, } \\
\text { pleasant surprise } \\
\text { amusement. However, } \\
\text { there was a question mark } \\
\text { about a feature of the } \\
\text { application, which could } \\
\text { be indicative of actionable } \\
\text { criticism }\end{array}$ \\
\hline
\end{tabular}

On the whole, when responses R5, R6, R7 and R8 are analyzed, what emerges is that the users are positive about the application that has been developed, 'save' for improvements that need to be done for the innovation to be creative. For instance, R5 opines that the application can be "very efficient" but it need to be made more accessible and the developers to explore more how they will generate revenue from the application. While the respondent voiced these suggested improvements, R5 still expressed strong pleasant feelings of desire, satisfaction and fascination, with some mild feelings of pleasant surprise and amusement. This was similarly the case in R6, who required that the application should be made more 'appealing' to the users, as well as to provide 'extra lines on the app'; R7, who warned on allowing free downloads and limiting the quantity of 'things' in the app; while R8 sought to focus on making the app 'foolproof'. All these suggested 'actions' were accompanied by pleasant feelings (mostly, D, S, F); which suggests that on the whole, the user feedback was supportive of the current application and the focus of the developers should be geared towards making the design better through the suggested improvements.

Developers must therefore seek to recognize feedback and be in a position to categorize such feelings accordingly. "Actionable Criticisms" are positive, thus the focus should be on how to adopt a positive approach to capturing feedback which is positive, that is, where users regard the innovation as creative (using expressed pleasant feelings), but make suggestions for further improvement. The importance of positive feelings, as feedback has long been recognized by scholars and practitioners alike (see Luthans, 2002) and if applied effectively, can be used to improve the systems development process.

\subsubsection{Recognizing "Negative Criticisms"}

Lack of originality is associated with applications that have profound negative criticism (Table 4).

Table 4 Recognizing "Negative Criticisms"

\begin{tabular}{|l|l|l|}
\hline Ref & Text: Excerpts & Discursive Analysis \\
\hline R9 & $\begin{array}{l}\text { Some people may } \\
\text { not afford the need }\end{array}$ & $\begin{array}{l}\text { There were situations where } \\
\text { respondents indicated that they } \\
\text { barely felt the emotion (desire, } \\
\text { [..]. People who do } \\
\text { not have smart } \\
\text { phones will not } \\
\text { access it. Children } \\
\text { will want their needy } \\
\text { parents to buy them } \\
\text { the negative emotions of } \\
\text { unpleasant surprise and } \\
\text { dissatisfaction. In such } \\
\text { situations, the feedback was } \\
\text { phones. on smart }\end{array}$ \\
largely "negative criticism". \\
\hline R10 & $\begin{array}{l}\text { This application is } \\
\text { not unique. It }\end{array}$ & $\begin{array}{l}\text { Feelings of desire and } \\
\text { satisfaction, coupled with mild }\end{array}$ \\
\hline
\end{tabular}




\begin{tabular}{|l|l|l|}
\hline R11 & $\begin{array}{l}\text { sometimes has some } \\
\text { mistakes and may } \\
\text { contain viruses. It is } \\
\text { complicated and } \\
\text { cannot be } \\
\text { understood easily. }\end{array}$ & $\begin{array}{l}\text { feelings of fascination, pleasant } \\
\text { surprise and amusement } \\
\text { resulted in some negative } \\
\text { criticism of the mobile } \\
\text { application. }\end{array}$ \\
$\begin{array}{l}\text { This is a basic } \\
\text { application which is } \\
\text { not needed, but cool. } \\
\text { The contact section } \\
\text { is not nice and it is } \\
\text { not easy to use. }\end{array}$ & $\begin{array}{l}\text { Feelings associated with such } \\
\text { applications include mild } \\
\text { feelings of desire, fascination, } \\
\text { satisfaction, boredom and } \\
\text { unpleasant surprise }\end{array}$ \\
\hline R12 & $\begin{array}{l}\text { It going to take a } \\
\text { long time uploading } \\
\text { the pictures of your } \\
\text { own cloths. Requires } \\
\text { a cell phone with a } \\
\text { strong camera }\end{array}$ & $\begin{array}{l}\text { Where feelings of amusements, } \\
\text { mild (desire, pleasant surprise), } \\
\text { contempt and dissatisfaction are } \\
\text { experienced, negative criticism } \\
\text { abound }\end{array}$ \\
\hline
\end{tabular}

The difference between "Actionable Criticisms" and "Negative Criticism" is in terms of the feelings (either mild pleasant feelings or unpleasant feelings in negative criticisms) expressed as well as the 'negativity' (in negative criticisms) of the criticisms. Responses R9 to R12 show that the expressed feelings are predominantly either mild pleasant feelings or unpleasant feelings (Table 4). In addition, the written and oral feedback given expresses serious flaws in the design of the mobile application, typically indicative of a major overall in the applications design. Thus the pointer is that the application is not acceptable in its current state and cannot be considered to be creative or innovative.

\subsubsection{Reconsidering "New Possibilities"}

The key to recognizing situations where users are questioning the feasibility of the current application rests on feedback that brings out unpleasant feelings and also raises several questions about the application (Table 5).

Table 5 Reconsidering "New Possibilities"

\begin{tabular}{|l|l|l|}
\hline Ref & Text: Excerpts & Discursive Analysis \\
\hline R13 & $\begin{array}{l}- \text { Is it easy to understand } \\
\text { for people new to its } \\
\text { content? } \\
\text {-Does it catch attention } \\
\text { in its appearance? } \\
\text {-Can it show me where I } \\
\text { can find students related } \\
\text { needs? } \\
\text {-Is it friendly for all } \\
\text { types of users? }\end{array}$ & $\begin{array}{l}\text { Many questions are } \\
\text { associated with mild } \\
\text { feelings of disgust, } \\
\text { dissatisfaction, boredom and } \\
\text { positive feelings of } \\
\text { fascination. }\end{array}$ \\
\hline R14 & $\begin{array}{l}\text { "Get more ways of } \\
\text { making the app eye } \\
\text { catching, so that many } \\
\text { people can join the ap. } \\
\text { How are people going to } \\
\text { their products } \\
\text { get } \\
\text { delivered to them?" }\end{array}$ & $\begin{array}{l}\text { Feelings of disgust, } \\
\text { unpleasant } \\
\text { dissatisfaction and mild } \\
\text { feelings of contempt and } \\
\text { boredom are associated with } \\
\text { comments that point out the } \\
\text { need for seeking new } \\
\text { possibilities for the design }\end{array}$ \\
\hline R15 & $\begin{array}{l}\text { The implementation of } \\
\text { There are also situations } \\
\text { where the respondents felt }\end{array}$ \\
\hline
\end{tabular}

\begin{tabular}{|c|c|c|}
\hline & $\begin{array}{l}\text { time slots will remain a } \\
\text { persistent issue. If they } \\
\text { were to implement this } \\
\text { system at other campus } \\
\text { restaurants, creating an } \\
\text { entirely new system will } \\
\text { cost a lot of money. }\end{array}$ & $\begin{array}{l}\text { desire and fascination and to } \\
\text { some extent, pleasant } \\
\text { surprise, satisfaction and } \\
\text { amusement. }\end{array}$ \\
\hline R16 & $\begin{array}{l}\text { The app sounds a lot like } \\
\text { the ClickUP system } \\
\text { already implemented (not } \\
\text { original). [...] Who is } \\
\text { the target audience, as } \\
\text { the app seems busy with } \\
\text { too many ideas that } \\
\text { don't get together? }\end{array}$ & $\begin{array}{l}\text { A number of questions are } \\
\text { raised when the emotion felt } \\
\text { is desire, satisfaction, but } \\
\text { with negative feelings of } \\
\text { contempt, } \text { unpleasant } \\
\text { surprise with slight feelings } \\
\text { of boredom and contempt. }\end{array}$ \\
\hline
\end{tabular}

A majority of the responses that questioned the feasibility of the application raised queries specific to the application, without necessarily giving suggestions for further improvements. Samples of some of the questions raised are depicted in Table 5 by respondents $\mathrm{R} 13$ to $\mathrm{R} 16$. We see such scenarios, where respondents provide "negative criticism" by raising questions related to the feasibility and logic of the innovation as a call to relook and re-think the whole design concept. This may require a totally new design or a redesign, whose objectives are not necessarily similar to earlier envisaged objectives. From an emotional design perspective, such evaluation should focus on how the users respond; thus if their feelings are predominantly captured as unpleasant or mild, coupled with responses that point to an infeasible solution; then the developers should focus on considering new possibilities all together.

\section{DISCUSSION OF FINDINGS}

The emphasis in the background of the study and in the literature review was to link the notion of creativity in innovations to emotional design. Part of the argument was that for a an innovative mobile application to be developed, user involvement should be inclusive and should not be restricted to the formal, rational approaches of requirements engineering only, but that feedback related to emotional feelings of users can be instrumental in realizing effective mobile applications design. The background was relevant for motivating for the need for evaluation of creative mobile innovations using emotional design. We structure this section by first making inferences from the analysis undertaken above and linking the results to current literature. Secondly, implications of the research findings are discussed, taking into account possible influences to theory, practice and methods.

In this section, we structure the discussion of results around the concept of 'emotional design' in information systems development (ISD) and its possible impact on limiting the effects of mis-information during the process of applications development. An argument is also advanced for encouraging a partnership in between developers and users in ensuring creative innovations are realized in mobile applications development.

\subsection{Emotional Design in Creative ISD}

The analyses conducted above and prior literature enables to make the following claims: that for more applications development to be more creative and innovative, emotional design should be part 
of the broader process of improving requirements engineering (RE) in ISD. The RE problem, known to be a persistent contributor to IT project failures, have previously been considered as a rational, formal process; and its ontology has previously been shown to be inadequate and deficient in mapping what successful and effective RE process is (see Jureta, Mylopoulos, \& Faulkner, 2008). In their conceptualization of RE, Jureta, Mylopoulos, \& Faulkner (2008) show that RE should consider concerns of users such as beliefs, desires, intentions, and attitudes. The ability to communicate such concerns requires the emotional involvement of the stakeholders and the analysis above, in a preliminary sense in the context of South Africa, provides a basis for making a claim for incorporating emotional evaluation in the process of RE in ISD.

This claim finds traction in recent literature. For instance, considering that the process of evaluation in ISD involves decision making at various stages (including RE), Morse (2014) links the process of decision making to powerful emotions such as desire; that these emotions affect the choices that we make. Obviously, in the interactive processes of making applications design choices between the developer and the user (and other stakeholders), the caveat for such influences of emotions would be for developers and other project leaders to consider ways of ensuring emotional user involvement to ensure effective designs. Using emotional designs in the process is by no means straightforward, rational or even easy; but the import of emotions in decision making can also not be wished away, thus designers need to consider propositions that encourage the use of emotional designs, complementary to other formal, logical approaches typically used in RE. Therefore, the use of Emocard in this research and other approaches suggested by "Wow" researchers ( see Desmet, Porcelijn, \& Van Dijk, 2007), while exploratory in nature, can be a foundation for more exploration to ingrain emotional design in ISD.

\subsection{Limiting Misinformation Effect in ISD}

We also make a claim based on an underlying principle linked to emotions: that the "misinformation effect" common in ISD can be minimized in situations where emotional feedback is genuine, for example in in requirements engineering (RE) problems.. Literature recognizes that during the process of RE, analysts may introduce misinformation in their discussions with users (Appan \& Browne, 2012). Misinformation can also be introduced, when users do not know what they want or when analysts are 'overconfident' about their abilities to understand user needs and go forth with the development process with minimal consulation with the users (Naidoo, 2012). In relating the problem of misinformation effect to our study, our interest is in how additional emotional engagement with users (and other stakeholders) througb various approaches can aid in mitigating the effects of the misinformation effect. The question is: How can emotional design be used to minimize the effect of misinformation?

First, and based on other studies that have been done, misinformation is exacerbated where there is mistrust (intentional or unintentional); yet research confirms that proper application and recognition of emotions can be instrumental in building trust, strengthening relationships, focusing energy, making trade-offs and learning from failure (Sundheim, 2014). Further, that emotions and feelings are essential to the intuitive ability of human beings to make good judgment (Hayashi, 2014), either as analyst or as users. So, while Kabaale, Kituyi, \& Mbarika (2014) question the 'practicality' of the RE process itself, we see deeper emotional engagement as a means to bridging the 'chasm' between users and analysts, which may help in reducing misinformation in RE. Thus, software development processes that encourage the use of and recognize the role of emotions in providing feedback are likely to impact positively in creation of innovative applications.

For instance, in this study, a likely scenario where users either provide negative criticism (Table 4) or question the feasibility of the application (Table 5) would be for the analysts to react by misinforming stakeholders. The proposition being made is that with emotional engagement, either trust is built, or; analysts will increasingly become aware of how to react to situations where stakeholders express negative criticism or question the logic or the feasibility of the application. David \& Congleton (2014) regard this as a process of emotional agility, in which analysts learn to effectively manage the negative thoughts and feelings, but with the intention 'turning around' the negative feelings for an effective software development process. In this sense, we therefore see emotional design as playing a critical role in minimizing misinformation in ISD.

\subsection{Emotional User Involvement for Creative Innovations}

The third claim we make is that users in ISD should be considered as co-developers of applications in order to realize true creativity and innovativeness. This is not a new claim, but we simply seek to expand the repertoire of what it means to be co-developers: moving beyond the formality of participatory design towards user involvement that captures their values through their feelings and emotions. The study reported in this study demonstrates that this is a perspective that needs to be considered during the process of ISD.

\section{CONCLUSIONS}

The present study has demonstrated that feelings in ISD can be evaluated using visual artifacts such as the Emocard illustrated throughout this paper. We make no claim to having extended theory related to "wow" research but link our contribution, though in a preliminary sense, to creating awareness and advocating for research that should ground emotional forms of design in processes of mobile applications development. Evaluation and our understanding of requirements engineering processes can therefore be enriched by using emotional designs to ensure the success of ISD projects. We believe that the theoretical perspective that elevates the role of feelings and emotions in improving user involvement processes in ISD can impact positively by helping in reducing persistent failure in realizing IT project objectives. It is important to realize that in no way are we belittling the formal and rational approaches of RE, but rather are advocating for additionally considering emotional evaluation as part of the repertoire of the process of RE.

We make some tentative implications related to theory, practice and methodology. The theoretical implication, which we may characterize as a call for action in IS research is that the use of emotional design in ISD should be of greater focus for IS researchers. The research reported in this study has demonstrated the efficacy of using emotional and visual approaches such as the use of the Emocard instrument in RE. Our engagement with the 
research in this domain contributes to the continuing accumulation knowledge about ICT practices in developing countries; which aid in extending and validating theory based on different contexts. Of course we recognize that this is an exploratory study, but nevertheless as a starting point for calling on IS researchers to start engaging with their 'feelings' more in order to advance the theory of user involvement in RE process.

From a methodological and context perspective, our use of action research procedures, though not unique to this study, has afforded us an opportunity as researchers to 'test' interventions in a context that we can classify as overwhelming. We say this since the study was undertaken in an experimental context that required administering and evaluating the effectiveness of a visual research instrument to over 1800 student of a large educational institution in South Africa. The success and the lessons arising therefore may be useful for the research in and teaching of design-based modules in contexts where large groups of respondents form part of the experiment.

\section{ACKNOWLEDGMENTS}

Our thanks go to Nelisiwe Nkosi and Thomas Dyzel for their research assistance.

\section{REFERENCES}

[1] Appan, R., \& Browne, G. J. (2012). The impact of analystinduced misinformation on the requirements elicitation process. MIS Quarterly, 36(1), 85-106.

[2] Arkhipenkov, S. (2012). Thinking About Programming: From Aristotle to Wittgenstein. Software Engineering Conference in Russia. Moscow.

[3] Beck, K., \& Andres, C. (2004). Extreme programming explained: embrace change. Addison-Wesley Professional.

[4] Boud, D., \& Walker, D. (1990). Making the most of experience. Studies in Continuing Education, 12(2), 61-80.

[5] Braun, V., \& Clarke, V. (2006). Using thematic analysis in psychology. Qualitative research in psychology, 3(2), 77101.

[6] Csikszentmihalyi, M. (1999). Implications of a systems perspective for the study of creativity. In M.

Csikszentmihalyi, Handbook of Creativity (pp. 313-335). New York: Cambridge University Press.

[7] David, S., \& Congleton, C. (2014). Emotional Agility. Harvard Business Review, pp. 88-93.

[8] Desmet, P., \& Hassenzahl, M. (2012). Towards happiness: Possibility-driven design. In Human-computer interaction: The agency perspective (pp. 3-27). Springer Berlin Heidelberg.

[9] Desmet, P. M., \& Pohlmeyer, A. E. (2013). Positive design: An introduction to design for subjective well-being. International Journal of Design, 7(3), 5-19.

[10] Desmet, P., Porcelijn, R., \& Van Dijk, M. B. (2007). Emotional Design; Application of a research-based design approach. Knowledge, Technology \& Policy, 20(3), 141-155.

[11] Dorst, K., \& Cross, N. (2001). Creativity in the design process: co-evolution of problem-solution. . Design studies, 22(5), 425-437.
[12] Gruner, S. (2011). Problems for a philosophy of software engineering. . Minds and Machines, 22(2), 275-299.

[13] Hartwick, J., \& Barki, H. (1994). Explaining the role of user participation in information system use. Management science, 40(4), 440-465.

[14] Hassenzah, M., \& Tractinsky , N. (2006). User experience-a research agenda. Behaviour \& Information Technology, 25(2), 91-97.

[15] Hayashi, A. M. (2014). When to Trust Your Gut. Harvard Business Review, pp. 80-87.

[16] Henfridsson, 0., \& Lindgren, R. (2010). User involvement in developing mobile and temporarily interconnected systems. Information Systems Journal, 20(2), 119-135.

[17] Jureta, I. J., Mylopoulos, J., \& Faulkner, S. (2008). Revisiting the core ontology and problem in requirements engineering. 16th IEEE International Requirements Engineering. IEEE.

[18] Kabaale, E., Kituyi, M., \& Mbarika, I. (2014). Requirements Engineering Process Improvement Challenges faced by Software SMEs in Uganda. International Journal of Computer Applications, 88(5), 20-25.

[19] Kamil, M. J., \& Abidin, S. Z. (2013). Unconscious Human Behavior at Visceral Level of Emotional Design. ProcediaSocial and Behavioral Sciences, 105, pp. 149-161.

[20] Lazarus, R. S. (1991). Emotion and adaptation. Oxford University Press.

[21] Luthans, F. (2002). Positive organizational behavior: Developing and managing psychological strengths. The Academy of Management Executive, 16(1), 57-72.

[22] Mann, D. (2002). Design for wow; an exciter hypothesis. Retrieved 06 08, 2014, from http://www.triz-journal.com

[23] Morse, G. (2014). Decisions and Desire. Harvard Business Review, pp. 72-79.

[24] Naidoo, R. (2012). 'Simply the best!', How should e-leaders manage overconfidence among IT professionals?. Sustainable e-Government and e-Business Innovations ( $E$ LEADERSHIP) 2012 e-Leadership Conference (pp. 1-9). IEEE.

[25] Norman, D. A. (2007). Emotional design: Why we love (or hate) everyday things. Basic books.

[26] Olsson, T., \& Salo, M. (2012). Narratives of satisfying and unsatisfying experiences of current mobile augmented reality applications. ACM annual conference on Human Factors in Computing Systems (pp. 2779-2788). ACM.

[27] Pyshkin, E. (2014). In the right order of brush strokes: a sketch of a software philosophy retrospective. SpringerPlus, 3(1), 1-6.

[28] Rowe, P. G. (1991). Design thinking. MIT press.

[29] Sawyer, K. R. (2012). Explaining Creativity: The Science of Innovation. New York: Oxford University Press.

[30] Sundheim, D. (2014). Good Leaders Get Emotional. Harvard Business Review, pp. 9-12.

[31] Terninko, J. (1995). Step by step QFD: Customer driven product design. Boca Raton, Florida: CRC. 
[32] Tractinsky, N. (1997). Aesthetics and apparent usability: empirically assessing cultural and methodological issues. ACM SIGCHI Conference on Human factors in computing systems. (pp. 115-122). ACM.

[33] Tractinsky, N. (2004). A few notes on the study of beauty in HCI. Human-Computer Interaction, 19(4), 351-357.
[34] Tractinsky, N., Katz, A. S., \& Ikar, D. (2000). What is beautiful is usable. Interacting with computers, 13(2), 127145.

[35] Romme, A. G. L. (2004). "Action research, emancipation and design thinking." Journal of Community \& Applied Social Psychology 14(6): 495-499. 